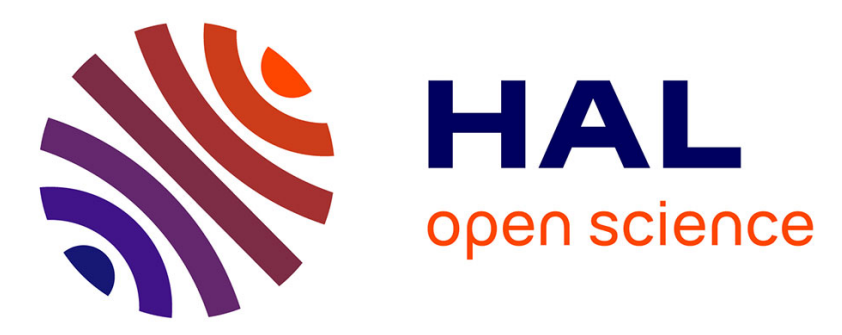

\title{
Unexpected bias of freeze-drying on the performance assessment of chemical oxidation of soils contaminated by polychlorinated biphenyls
}

O. Monfort, K. Hanna

\section{- To cite this version:}

O. Monfort, K. Hanna. Unexpected bias of freeze-drying on the performance assessment of chemical oxidation of soils contaminated by polychlorinated biphenyls. Environmental Chemistry Letters, 2019, 17 (3), pp.1391-1396. 10.1007/s10311-019-00870-4 . hal-02090008

HAL Id: hal-02090008

https://hal-univ-rennes1.archives-ouvertes.fr/hal-02090008

Submitted on 17 Apr 2019

HAL is a multi-disciplinary open access archive for the deposit and dissemination of scientific research documents, whether they are published or not. The documents may come from teaching and research institutions in France or abroad, or from public or private research centers.
L'archive ouverte pluridisciplinaire HAL, est destinée au dépôt et à la diffusion de documents scientifiques de niveau recherche, publiés ou non, émanant des établissements d'enseignement et de recherche français ou étrangers, des laboratoires publics ou privés. 
How freezing and the freeze-drying affect the performance assessment of chemical oxidation in soil contaminated by polychlorobiphenyls

\author{
Olivier Monfort ${ }^{* \dagger}$ and Khalil Hanna
}

Univ Rennes, Ecole Nationale Supérieure de Chimie de Rennes, CNRS, ISCR-UMR 6226, F35000 Rennes, France

*correspondence: olivier.monfort@uca.fr

†permanent address: Université Clermont Auvergne, CNRS, SIGMA Clermont, Institut de Chimie de Clermont-Ferrand, F-63000 Clermont-Ferrand, France

Keywords: freezing effect; soil; ferrate; chemical oxidaion; PCBs

\begin{abstract}
Processes based on chemical oxidation are widely used for environmental remediation. Analysis of environmental samples such as soils often requires a freeze-drying step prior measurement of the concentration of contaminants. However, the effect of freezing on quantification of the removal efficiency is poorly known. Here we studied the removal of polychlorinated biphenyls (PCBs) in contaminated soils using $\mathrm{H}_{2} \mathrm{O}_{2}$, persulfate, permanganate and ferrate(VI). To assess the chemical oxidation performance, soil samples were freeze-dried, extracted with hexane and PCBs were quantified in the extract by gas chromatography-mass spectrometry. Unexpectedly, in batch samples which were freezedried after 5 minutes of ferrate( $\mathrm{VI})$ oxidation, the removal extent of PCBs was about 2 times higher than in samples lyophilized after 3 hours of reaction time (from 30 to $60 \%$ of degradation extent of PCBs). Similar oxidation treatments performed at $-20^{\circ} \mathrm{C}$ (instead of room temperature) showed that the enhanced degradation extent in soil is related to freezing conditions. This phenomenon is explained by the freezing concentration effect, i.e. the increased concentration of reactants in the liquid brine. Although this freezing effect is already known for aqueous media, it is the first time this is demonstrated in heterogeneous soil system, particularly for their remediation by chemical oxidation technology. The nonconsideration of this unforeseen effect during the soil preparation in laboratory studies may lead to an incorrect assessment of oxidation performance.
\end{abstract}




\section{Introduction}

In-situ chemical oxidation (ISCO) is an emerging technology for the remediation of soil and groundwater, which remains a point of extensive investigation within the field and a focus of a growing number of published studies (ITRC 2005; Siegrist 2011). A laboratory assessment is often designed to evaluate the effectiveness of using reactive oxidants to convert hazardous contaminants into nonhazardous or less toxic compounds in soils (ITRC 2005; Siegrist 2011). In most of laboratory studies, the oxidation tests are performed through a direct mixing of chemical oxidants with the investigated soil, and then determination of residual amount of contaminants after a certain period of time. Prior to analysis, the treated soil is frozen and water removed by sublimation from ice (i.e. freeze-drying process also called lyophilization). Then, the residual concentration of target contaminants in the freeze-dried soil can be quantified by extraction using organic solvent.

The low temperature dehydration process is a necessary step in the soil preparation (Monfort 2019; Tang 2015; Rybnikova 2016), thus allowing an efficient extraction of target molecules using organic solvent. Another reason is the preservation of all physical and chemical properties of the soil with no impact on the reaction performance. The treated soil is also pre-frozen in a freezer or liquid nitrogen before being placed into the freeze-dryer to avoid shrinkage, thus facilitating faster removal of water vapor during sublimation (Zhang 2018). Freeze-drying process, contrary to freeze-thaw cycles, increases the stability of soil aggregates (Dagesse 2011), thus preserving the soil integrity. Because a rapid freezing may be utilized to quench the reactions in aqueous media (Monfort 2019; Tang 2015; Rybnikova 2016), lyophilization followed by solvent extraction of batch samples is an adequate technique for kinetic studies.

The effect of freezing is known to alter specific chemical reactions (O'Concubhair 2013). The freezing effect is often associated to reactions, which occur in the cryosphere such as in upper stratosphere or polar regions (snowpack, freezing fogs, snowflakes) (O'Concubhair 2013). Several studies have already highlighted the effect of freezing to explain the oxidation of nitrites into nitrate in the permafrost or in polar regions (Kim 2017; Sun 2017; Takenaka 1992), the dissolution of iron oxides in atmospheric mineral dust (Jeong 2012; Jeong 2015), the reduction of chromate and 
bromate in frozen solution by organic compound as electron donor (Ju 2017; Kim 2011; Kim 2015; Min 2017), or the activation of periodate in frozen solution for enhanced degradation of organic contaminants (Choi 2018). However, the freezing effect has never been investigated in the context of soil remediation where freezedrying is commonly used in the preparation of soil samples (Monfort 2019; Tang 2015; Rybnikova 2016).

The present work arises from counterintuitive results observed during a kinetic study of chemical oxidation in soil. In an exploratory study from our group (Monfort 2019), the ability of chemical oxidation to remove polychlorinated biphenyls (PCBs) from an aged contaminated soil using ferrate(VI) has been evaluated under various experimental conditions (liquid/solid ratio and oxidant type and dose) after $24 \mathrm{~h}$ of reaction time, but no detailed kinetic study has been performed. In the present work, we decided to investigate the first kinetic stage (i.e. at $\mathrm{t}<60 \mathrm{~min}$ ) because (i) the reactive oxidant is supposed to be rapidly decomposed in soil and (ii) significant knowledge on the action of ferrate(VI) considered as an environmentally friendly oxidant in heterogeneous soil media is needed. We also compare with common oxidants, widely used in soil remediation studies, persulfate $\left(\mathrm{K}_{2} \mathrm{~S}_{2} \mathrm{O}_{8}\right)$ and permanganate $\left(\mathrm{KMnO}_{4}\right)$. All the three oxidants may act through electron transfer (Fang 2013; Kim 2018; Sharma 2013; Sharma 2015), though a radical pathway can be expected for activated persulfate (Fang 2013; Tang 2015). For the ferrate(VI), electron transfer accompanied by oxygen atom transfer may occur with the target contaminants leading to the formation of oxidized byproducts, while ferrate(VI) is simultaneously transformed into Fe(III)-oxyhydroxides (Sharma 2013; Sharma 2015). Despite the wide application of chemical oxidation in soil cleanup technologies and the potential advantages offered by the use of this "green" oxidant, reports on the use of ferrate(VI) oxidation in soil remediation are very scarce (Rai 2018). As the chemical oxidation is one of the most extensively used methods in the remediation of soil and groundwater, this work calls for an accurate evaluation of freezing and freeze-drying impacts on the oxidation performance, but may also have broader implications in understanding oxidation mechanisms in soils undergoing freeze-thaw cycles or in other soil treatment and pretreatment processes (Aresta 2004; Li 2018; Quiroz 2009; Singh 2017). 


\section{Materials and methods}

Potassium ferrate, potassium persulfate and potassium permanganate were purchased from Nanolron (Czech Republic), Merck and Prolabo, respectively. The investigated soil was provided by the French Environment and Energy Management Agency (ADEME). The main characteristics of the soil are summarized in Table S1 (See Electronic Supplementary Information). Briefly, the tested soil contains high amount of carbonates, thus resulting in alkaline $\mathrm{pH}$. High amount of PCBs $(1018 \mathrm{mg} / \mathrm{kg})$ are present, out of which more than $50 \%$ is composed of hexa-chlorinated biphenyls and approximatively $45 \%$ of penta- and hepta-chlorinated biphenyls (Table S2).

Prior to chemical oxidation, the soil is dried, crushed and passed through $500 \mu \mathrm{m}$ sieve. All experiments are performed in batch mode, where $2 \mathrm{~g}$ of soil is first mixed with $2 \mathrm{~mL}$ of deionized water (i.e. liquid-to-solid ratio of 1 ). Then, the optimized amount of ferrate(VI), persulfate or permanganate is added directly to the soil to trigger the chemical oxidation (Monfort 2019). For the kinetic experiments, each batch sample is pre-frozen in liquid nitrogen for 2 minutes and then transferred into the freeze-dryer (Labconco Freezon 2.5) for $24 \mathrm{~h}$.

To rebut a possible effect of a simple temperature change over a freezing effect, additional tests at different temperatures have also been performed including $-20^{\circ} \mathrm{C}$ (freezer), $4{ }^{\circ} \mathrm{C}$ (cold chamber), room temperature $\left(+20^{\circ} \mathrm{C}\right.$ ) and $+40{ }^{\circ} \mathrm{C}$ for 24 hours. After each experiment, pre-freezing process was applied as described above. As the eutectic temperatures of potassium persulfate, ferrate and permanganate are not known, we assume they are closer to the that of $\mathrm{H}_{2} \mathrm{O}_{2}$ solution (i.e. $-50{ }^{\circ} \mathrm{C}$ ) (Foley 1951; Kim 2015).

The chemical oxidation performance for soil remediation is evaluated by the quantification of PCBs using Gas Chromatography-Mass Spectrometry (GC-MS, Perkin Elmer Clarus 500). The detailed procedure is reported in a previous study (Monfort 2019). Before GC-MS analysis, the soil has been first freeze-dried. Then PCBs are extracted by accelerated solvent extraction (Dionex ASE 300) in hexane, and the obtained extract is subsequently pre-concentrated prior its analysis by GC-MS using PCB209 (Sigma-Aldrich) as internal standard. Because the fine particles tend to fly off 
with the water vapour (Brydon 1963), loss of material during freeze-drying may occur through ejection of dried material (Morris 1972). Assessment of PCB amounts in blank tests has easily permitted to exclude this hypothesis, since there is no change of the initial amount of PCBs.

\section{Results and discussion}

The kinetic degradation of PCBs in soil using ferrate(VI) exhibits an unexpected $U$-shaped curve, i.e. the removal extent of PCBs at the first minutes was about 2 times higher than at later reaction times (Fig. 1). While degradation reactions traditionally follow fixed-order kinetics, the relationship of PCB concentration decay versus time observed here raises questions, especially about the ferrate(VI) oxidation mechanism. Indeed, if we consider first-order kinetic reaction and calculated the initial rate constant $\left(k_{\text {initial }}\right)$ over the first stage of reaction (i.e. concentration drop step) by plotting a linear regression of $-\ln \left(C / C_{0}\right)$ versus time, we found a much higher value $\left(0.25 \mathrm{~min}^{-1}\right)$ than that estimated if we assume a $1^{\text {st }}$ order kinetic reaction $(0.002$ $\mathrm{min}^{-1}$ ) based on the plateau achieved in case of ferrate(VI) (dashed lines, Fig.1). Degradation kinetics with permanganate or persulfate also present the same anomaly but at much smaller extents since they show more classical behavior (Fig. 1). The sharp decay in contaminant concentration may result from fast consumption of oxidant and/or low availability of PCBs which are known to be highly recalcitrant to degradation (Monfort 2019).

It should be noted that each batch sample used to determine the degradation extent (just described above) has undergone the same preparation procedures, i.e. pre-freezing, freeze-drying and solvent extraction, but higher PCB degradation extents are only observed at the beginning of oxidation reaction (i.e. within the first 30 minutes), especially for ferrate(VI) oxidation (Fig. 1). Due to the high reactivity (or very low stability) of ferrate(VI), its concentration must be rapidly depleted in soil over time, and thus only the first samples (i.e. for $\mathrm{t}<60 \mathrm{~min}$ ) still contain a significant amount of ferrate(VI). Indeed, a decomposition test in distilled water shows that almost $50 \%$ of $20 \mu \mathrm{M}$ ferrate(VI) decomposed after 60 minutes at $\mathrm{pH} 7$ (not shown). Although it is difficult to determine the ferrate(VI) concentration in treated soil, especially at very low liquid-to-solid ratio, we may assume that the ferrate(VI) 
decomposition is much faster in soil than in water, likely due to the presence of various mineral and organic soil constituents. Therefore, the enhancement effect observed here is only effective when the ferrate( $\mathrm{VI})$ concentration is high enough in soil to induce further degradation.

As previously mentioned in Materials \& Methods section, and to improve the freeze-drying process, the treated soil was rapidly pre-frozen in liquid nitrogen for 2 minutes and then transferred in freeze-dryer. In this case, the eutectic point is quickly reached and smaller ice crystals are expected to form (Choi 2018; Kim 2015). That also may stop the oxidation reaction in the soil containing oxidant during the kinetic assessment without adding a new chemical reagent in soil (Tang 2015; Rybnikova 2016).

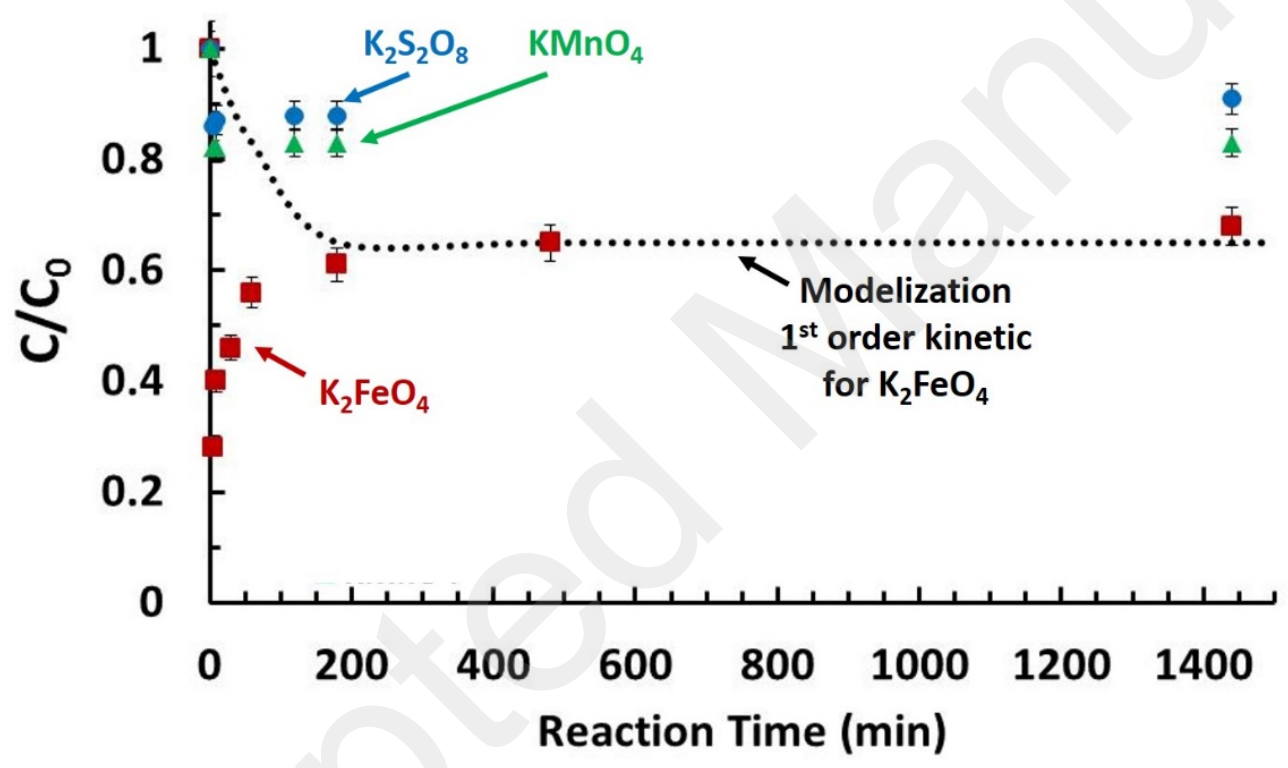

Figure 1. Kinetics of polychlorinated biphenyls (PCBs) removal in soil by potassium ferrate $(\mathrm{VI})\left(\mathrm{K}_{2} \mathrm{FeO}_{4}\right)$ at $0.5 \mathrm{mmol} / \mathrm{g}$ of soil, potassium permanganate $\left(\mathrm{KMnO}_{4}\right)$ at 0.2 $\mathrm{mmol} / \mathrm{g}$ of soil and potassium persulfate $\left(\mathrm{K}_{2} \mathrm{~S}_{2} \mathrm{O}_{8}\right)$ at $0.2 \mathrm{mmol} / \mathrm{g}$ of soil. All the experiments are performed at $\mathrm{T}=20 \pm 1^{\circ} \mathrm{C}$. The dashed lines represent what it was expected to observe for a classical $1^{\text {st }}$ order kinetic model in case of ferrate(VI) oxidation.

To check whether the higher degradation extents observed at the beginning of the reaction in Fig. 1 results from a temperature-dependent mechanism, chemical oxidation tests using ferrate( $\mathrm{VI})$, permanganate or persulfate were performed at 4, 20 and $40{ }^{\circ} \mathrm{C}$. Over this narrow temperature range, the degradation extents of $\mathrm{PCBs}$ 
using ferrate(VI) oxidation vary between 29 and 34\%, which is in the margin error of $5 \%$. Similarly, the degradation extents oscillate between 7 and $9 \%$ for persulfate, and 10 and $13 \%$ for permanganate. Therefore, the PCBs degradation in the soil is temperature independent under our experimental conditions.

To test how the freezing impacts the degradation extent, we perform oxidation tests in soil at $-20{ }^{\circ} \mathrm{C}$ (a freezing temperature typically used in literature (Choi 2018; Jeong 2015; Kim 2015; Kim 2017; Min 2017)), and compare with those determined at room temperature $\left(20^{\circ} \mathrm{C}\right)$ for the same reaction time $(24 \mathrm{~h})$. This freezing temperature $\left(-20^{\circ} \mathrm{C}\right)$ was also chosen because it is above the eutectic point of oxidant solution (supposed here as around $-50{ }^{\circ} \mathrm{C}$, as for a $\mathrm{H}_{2} \mathrm{O}_{2}$ solution (Foley 1951; kim 2015)). Furthermore, different oxidant concentrations are also tested to address the potential limitation related to oxidant dose at the freezing temperature (Fig. 2 and S1). When the treated soil was aged at $-20{ }^{\circ} \mathrm{C}$, higher PCB degradation extents (than those obtained at $+20^{\circ} \mathrm{C}$ ) were achieved whatever the tested oxidant dose. This phenomenon is observed for persulfate and permanganate, but to a lesser extent (Fig. S1). The considerable effect of freezing observed in the case of ferrate(VI) is likely due to its higher efficiency for PCB degradation in soil compared to other tested oxidants, and because its efficiency clearly increases with ferrate(VI) concentration increasing (Fig. 2). Similar to ferrate oxidation in homogeneous aqueous solutions (Eng 2006; Feng 2017; Homolkova 2017), an exponential relationship of PCB removal with oxidant dose can be observed (Fig. 2). Even though it is a mathematical correlation, the observed behaviour may suggest that there are other limitation factors than oxidant dose for total removal of PCBs in soil (Monfort 2019).

Although the freezing effect has been never reported for the chemical oxidation processes in soil, it is known that this effect may accelerate reaction rate, through an increase of reactants concentration in the liquid brine (i.e. reactants are expelled from the growing ice phase) but also a significant change in pH (Butler 2002; Jeong 2015; Kim 2015; O'Concubhair 2013). The latter can be explained by the accumulation of $\mathrm{H}^{+}$or $\mathrm{HO}^{-}$in the liquid brine, which is referred as the "freeze concentration effect" (Butler 2002; Jeong 2015; O'Concubhair 2013). We thus conclude that the enhancement of $\mathrm{Fe}(\mathrm{VI})$ oxidation in soil takes place during the fast 
frozen step and before reaching the eutectic point. Since ferrate(VI) oxidation is a concentration-dependent process (Fig. 2), Fe(VI) can be freeze-concentrated in the ice grain boundary region along with the soil particles, thus accelerating the reaction rate.

A further modification, which may occur during the freezing process, is $\mathrm{pH}$ change (Choi 2018). As the soil has an alkaline $\mathrm{pH}$, an increase of $\mathrm{OH}^{-}$concentration with the freezing concentration effect may take place. This $\mathrm{pH}$ increase might also affect the action of persulfate, since it is more efficient under acidic conditions (Fang 2013; Tang 2015), but not that of permanganate which is pH independent (Kim 2018; Waldemer 2006). In the case of ferrate, a pH increase may affect the molecular speciation of ferrate( $\mathrm{VI})$. At high $\mathrm{pH}$, the dominant ferrate( $\mathrm{VI})$ form is $\mathrm{FeO}_{4}{ }^{2-}$, which is the most stable species (Choi 2018; Sharma 2013; Sharma 2015).

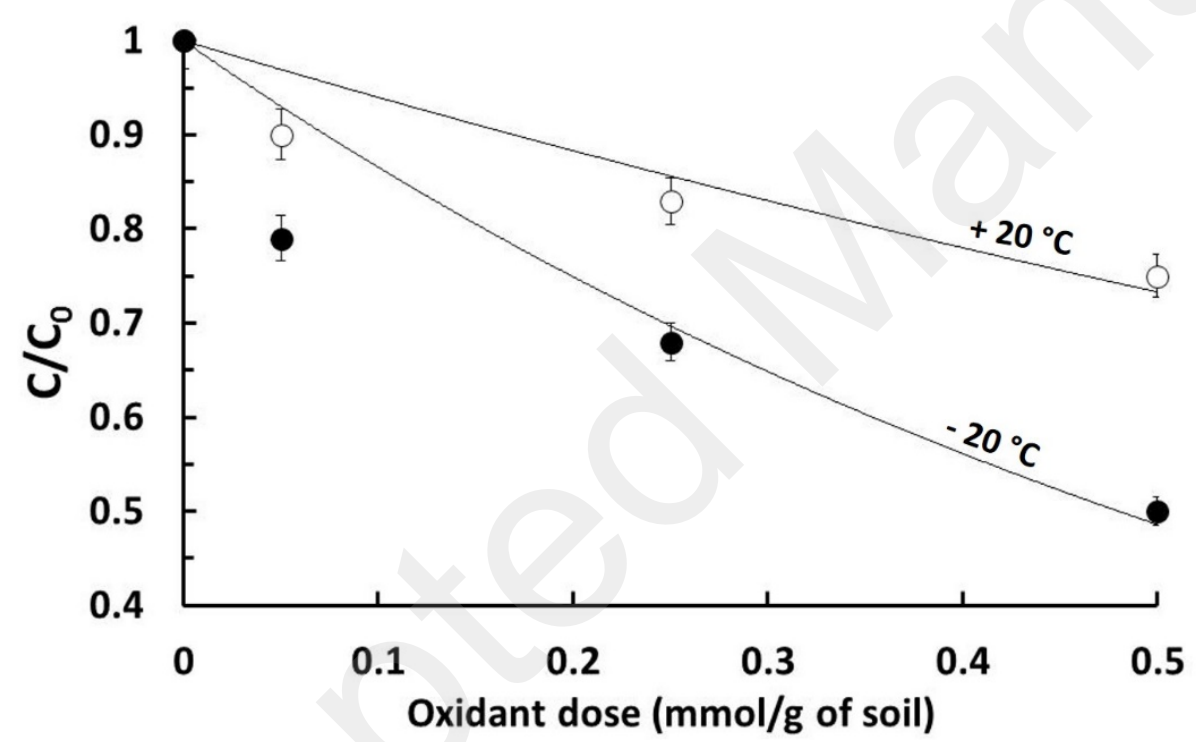

Figure 2. Removal extent of polychlorinated biphenyls (PCBs) in soil as a function of ferrate(VI) dose after 24 hours of reaction time at $-20 \pm 1{ }^{\circ} \mathrm{C}$ (freezing) and $+20 \pm 1{ }^{\circ} \mathrm{C}$ (room temperature). Solid lines are empricial models as $C / C_{0}=e^{-x D}$ with $x=1.44$ and 0.62 at $-20 \pm 1{ }^{\circ} \mathrm{C}$ and $+20 \pm 1{ }^{\circ} \mathrm{C}$, respectively, and $D$ is the dose of ferrate(VI).

As an attempt to explain the improvement of $P C B$ degradation in soil upon freezing, we discuss here how grain boundary regions are formed (Jeong 2015; Ji 2018; Peppin 2013; Perrott 1977; Xu 2018) when soil containing water and solid particles is frozen at $-20^{\circ} \mathrm{C}$, i.e. above its "eutectic point" where ice crystals and liquid brine co-exist. In a heterogeneous system, solid particles may constitute nucleation 
sites facilitating the formation of ice, as compared to homogeneous freezing where ice can form in the absence of any nuclei (Jeong 2015). However, the ice growing and ice crystal size depends on how fast the treated soil is frozen, while the volume of liquid brine is inversely proportional to the size of the ice crystals (Choi 2018; Kim 2015). If large ice crystals are formed, fine soil particles may be expelled from ice into the liquid brine (Fig. 3, right). In this confined zone, the finer particles containing probably the PCBs (Perad 1996; Rybnikova 2016) react with the freeze-concentrated oxidant. Indeed, PCBs, that are hydrophobic compounds, are usually located on soil organic matter or silts and clays containing high extent of organic carbon, which account to the finest fraction of soil (Kampire 2017; Wilcke 1998).

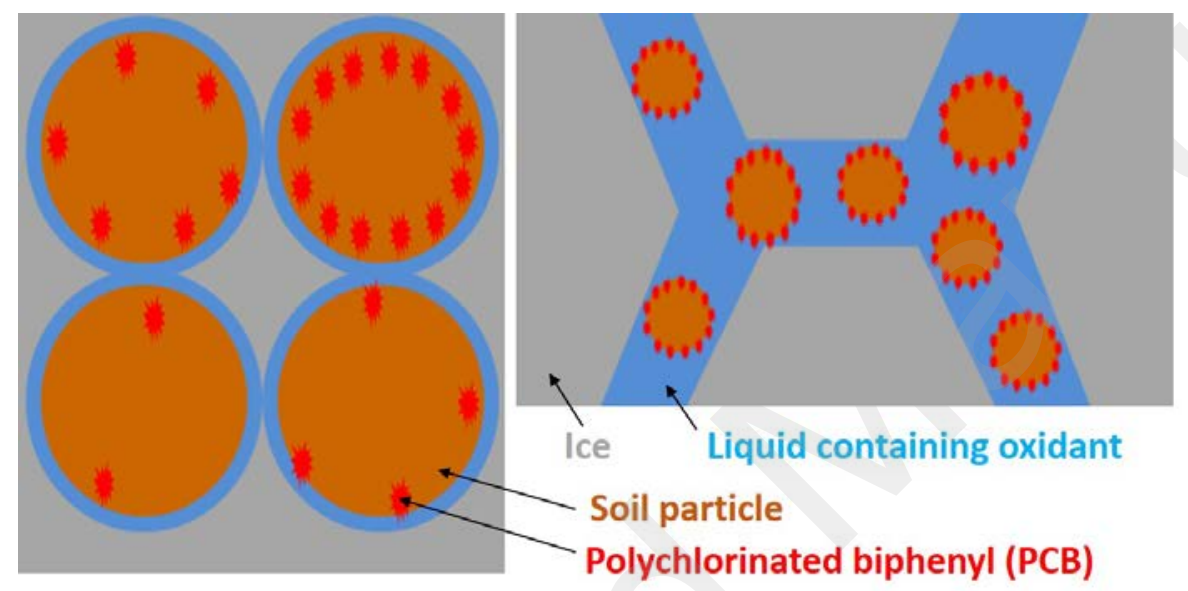

Figure 3. Representation of two conceptualized pathways for the freezing effect in soil. The soil particles containing polychlorinated biphenyls (PCBs) are either covered by pre-melted films (left) or expelled from ice crystals in the liquid brine where oxidation reaction occurs (right).

A second possibility is that upon freezing, pre-melted films are formed between the surfaces of soil grains and ice lens (Ji 2018; Peppin 2013; Xu 2018). This pre-melted film contains unfrozen water where ferrate(VI) is in direct contact with the contaminated particles (Fig. 3, left). In both pictures, the freezing effect gives rise to a favorable microenvironment in ice grain boundary where ferrate(VI) and PCBs come into contact. Therefore, the contact between the oxidant and the contaminant, which is the most limiting factor in in-situ chemical oxidation technologies, may be optimized under freezing conditions. 


\section{Conclusions}

The effect of freezing during the freeze-drying process of soil may have a significant impact on chemical reactions involved in soil remediation process. Consequently, more attention should be paid to the soil preparation and the bias that the soil freezing may introduce, and especially during the determination of kinetic parameters.

It is worth noting that the presently investigated soil with an aged contamination and very recalcitrant compounds such as PCBs may not be appropriate to clearly highlight the freezing effect in soil remediation. Nevertheless, this novel finding calls for new studies on different soil types along these lines.

\section{Acknowledgement}

We wish to acknowledge the French Environment and Energy Management Agency (ADEME) for the financial support (No. 1472C0030) and for providing the aged PCB contaminated soil.

\section{References}

Aresta M, Dibenedetto A, Fragale C et al (2004) High-energy milling to decontaminate soils polluted by polychlorobiphenyls and atrazine. Environ. Chem. Lett. 2:1-4. Doi: 10.1007/s10311-003-0057-0

Brydon JE, Rice HM, Scott GC (1963) The recovery of clays from suspension by freezedrying. Can. J. Soil Sci. 43:404-405

Butler MF (2002) Freeze concentration of solutes at the ice/solution interface studied by optical interferometry. Cryst. Growth Des. 2(6):541-548. Doi: 10.1021/cg025591e

Choi Y, Yoon HI, Lee C et al (2018) Activation of periodate by freezing for the degradation of aqueous organic pollutants. Environ. Sci. Technol. 52:5378-5385. Doi: 10.1021/acs.est.8b00281

Dagesse D (2011) Effect of Freeze-Drying on Soil Aggregate Stability. SSSAJ 75(6):21112121. Doi: $10.2136 /$ sssaj2010.0287

Eng YY, Sharma VK, Ray AK (2006) Ferrate(VI): Green chemistry oxidant for degradation of cationic surfactant. Chemosphere 63:1785-1790. Doi:

10.1016/j.chemosphere.2005.08.062 
Fang GD, Dionysiou DD, Zhou DM et al (2013) Transformation of polychlorinated biphenyls by persulfate at ambient temperature. Chemosphere 90:1573-1580. Doi: 10.1016/j.chemosphere.2012.07.047

Feng M, Czimas L, Wang Z et al (2017) Activation of ferrate(VI) by ammonia in oxidation of flumequine: Kinetics, transformation products, and antibacterial activity assessment. Chem. Eng. J. 323:584-591. Doi: 10.1016/j.cej.2017.04.123

Foley WT, Giguère PA (1951) Hydrogen peroxide and its analogues: II. phase equilibrium in the system hydrogen peroxide - water. Can. J. Chem. 29:123-132

Homolkova M, Hrabak P, Graham N et al (2017) A study of the reaction of ferrate with pentachlorophenol - kinetics and degradation products. Water Sci. Technol. 75:189-195. Doi: $10.2166 /$ wst.2016.496

Interstate Technology \& Regulatory Council (2005) Technical and regulatory guidance for in situ chemical oxidation of contaminated soil and groundwater. ITRC, Washington DC

Jeong D, Kim K, Choi W (2012) Accelerated dissolution of iron oxides in ice. Atmos. Chem. Phys. 12:11125-11133. Doi: 10.5194/acp-12-11125-2012

Jeong D, Kim K, Min DW et al (2015) Freezing-enhanced dissolution of iron oxides: Effects of inorganic acid anions. Environ. Sci. Technol. 49:12816-12822. Doi: 10.1021/acs.est.5b04211

Ji Y, Zhou G, Hall MR (2018) Frost heave and frost heaving-induced pressure under various restraints and thermal gradients during the coupled thermal-hydro processes in freezing soil. Bull. Eng. Geol. Environ. Doi: 10.1007/s10064-018-1345-z

Ju J, Kim J, Vetrakova L et al (2017) Accelerated redox reaction between chromate and phenolic pollutants during freezing. J. Hazard. Mater. 329:330-338. Doi: 10.1016/j.jhazmat.2017.01.031

Kampire E, Rubidge G, Adams JB (2017) Characterization of polychlorinated biphenyls in surface sediments of the North End Lake, Port Elizabeth, South Africa. Water S. A. 43(4):646-654. Doi: 10.4314/wsa.v43i4.12

Kim K, Choi W (2011) Enhanced redox conversion of chromate and arsenite in ice. Environ. Sci. Technol. 45:2202-2208. Doi: 10.1021/es103513u 
Kim K, Kim J, Bokare AD et al (2015) Enhanced removal of hexavalent chromium in the presence of $\mathrm{H} 2 \mathrm{O} 2$ in frozen aqueous solutions. Environ. Sci. Technol. 49:10937-10944. Doi: 10.1021/acs.est.5b02702

Kim K, Chung HY, Ju J et al (2017) Freezing-enhanced reduction of chromate by nitrite. Sci. Tot. Environ. 590-591:107-113. Doi: 10.1016/j.scitotenv.2017.02.176

Kim MS, Lee HJ, Lee KM et al (2018) Oxidation of microcystins by permanganate: $\mathrm{pH}$ and temperature-dependent kinetics, effect of DOM characteristics, and oxidation mechanism revisited. Environ. Sci. Technol. 52:7054-7063. Doi: 10.1021/acs.est.8b01447

Li C, Ding S, Yang L et al (2018) Diffusive gradients in thin films: devices, materials and applications. Environ. Chem. Lett. Doi: 10.1007/s10311-018-00839-9

Min DW, Choi W (2017) Accelerated reduction of bromate in frozen solution. Environ. Sci. Technol. 51:8368-8375. Doi: 10.1021/acs.est.7b00915

Monfort O, Usman M, Soutrel I et al (2019) Ferrate(VI) based chemical oxidation for the remediation of aged $\mathrm{PCB}$ contaminated soil: Comparison with conventional oxidants and study of limiting factors. Chem. Eng. J. 355:109-117. Doi: 10.1016/j.cej.2018.08.116

Morris ET, Darlow HM (1972) A safety container for use when freeze-drying infected materials. Meded. Lab. Tech. 29:417-418

O'Concubhair R, Sodeau JR (2013) The effect of freezing on reactions with environmental impact. Acc. Chem. Res. 46(11):2716-2724. Doi: 10.1021/ar400114e

Peppin SSL, Style RW (2013) The physics of frost heave and ice-lens growth. Vadose Zone J. Doi: 10.2136/vzj2012.0049

Perard C, Budzinski H, Garrigues P (1996) Grain-size distribution of polychlorinatedbiphenyls in coastal sediments. Environ. Sci. Technol. 30(9):2776-2783. Doi: 10.1021/es9600035

Perrott KW (1977) Freeze-drying of soil clays. Geoderma 17:219-224. Doi: 10.1016/0016-7061(77)90052-0

Quiroz R, Popp P, Barra R (2008) Analysis of PCB level in snow from the Aconcagua Mountain (Southern Andes) using the stir bar sorptive extraction. Environ. Chem. Lett. 7:283-288. Doi: 10.1007/s10311-008-0164-z 
Rai PK, Lee J, Kailasa SK et al (2018) A critical review of ferrate(VI)-based remediation of soil and groundwater. Environ. Res. 160:420-448. Doi: 10.1016/j.envres.2017.10.016

Rybnikova V, Usman M, Hanna K (2016) Removal of PCBs in contaminated soils by means of chemical reduction and advanced oxidation processes. Environ. Sci. Pollut. Res. 23(17):17035-17048. Doi: 10.1007/s11356-016-6881-0

Sharma VK (2013) Ferrate(VI) and ferrate(V) oxidation of organic compounds: Kinetics and mechanism. Coord. Chem. Rev. 257:495-510. Doi: 10.1016/j.ccr.2012.04.014

Sharma VK, Zboril R, Varma RS (2015) Ferrates: greener oxidants with multimodal action in water treatment technologies. Acc. Chem. Res. 48:182-191. Doi: 10.1021/ar5004219

Siegrist RL, Crimi M, Simpkin TJ (2011) In situ chemical oxidation for groundwater remediation. Springer, Berlin. Doi: 10.1007/978-1-4419-7826-4

Singh S, Kumar V, Chauhan A et al (2017) Toxicity, degradation and analysis of the herbicide atrazine. Environ. Chem. Lett. 16:211-237. Doi: 10.1007/s10311-017-0665-8

Sun F, Xiao Y, Wu D et al (2017) Nitrite-driven abiotic transformation of sulfonamide micropollutants during freezing process. Chem. Eng. J. 327:1128-1134. Doi: 10.1016/j.cej.2017.07.005

Takenaka N, Ueda A, Maeda Y (1992) Acceleration of the rate of nitrite oxidation by freezing in aqueous solution. Nature 358:736-738. Doi: 10.1038/358736a0

Tang X, Hashmi MZ, Zeng B et al (2015) Application of iron-activated persulfate oxidation for the degradation of PCBs in soil. Chem. Eng. J. 279:673-680. Doi: 10.1016/j.cej.2015.05.059

Waldemer RH, Tratnyek PG (2006) Kinetics of contaminant degradation by permanganate. Environ. Sci. Technol. 40:1055-1061. Doi: 10.1021/es051330s

Wilcke W, Zech W (1998) Polychlorinated biphenyls (PCBs) in bulk soil and particle size separates of soils in a rural community. Z. Pflanzenernahr. Bodenk. 161:289-295. Doi: 10.1002/jpln.1998.3581610316

Xu F, Zhang Y, Jin G et al (2018) Three phase heat and mass transfer model for unsaturated soil freezing process: Part 1 - model development. Open Phys. 16:75-83. Doi: 10.1515/phys-2018-0014 
Zhang $\mathrm{H}$ (2018) Ice templating and freeze-drying for porous materials and their applications. Wiley-VCH, Weinheim. Doi: 10.1002/9783527807390 